\title{
Development of model of the quality of the appearance of paint and varnish coatings
}

\author{
Valentina Loganina ${ }^{1, *}$ \\ ${ }^{1}$ Penza State University of Architecture and Construction Street Titov, 28, 440028 Penza, \\ Russia
}

\begin{abstract}
The regularities of the formation of the quality of the appearance of coatings from the rheological and technological properties of colorful compositions are established. It was revealed that with an increase in the surface tension of paint, a lower quality of the appearance of the resulting coating is observed. With an increase in the porosity of the substrate, an increase in the surface roughness of the coatings is observed. A model of the appearance quality of coatings is proposed depending on the porosity of the substrate and the surface tension of the paint composition
\end{abstract}

\section{Introduction}

Coatings for finishing facades, performing aesthetic protective functions, must have a high quality appearance. By the quality of appearance means the presence of defects (inclusions, streaks, shagreen, strokes and scratches, waviness, variability) paintwork. The presence of defects on the surface of the paintwork depends on the quality class of the appearance[ 1-3].

The quality of the appearance of coatings is determined by the degree of surface preparation of the substrate, which is characterized by an index of surface porosity. It has been established, that with a surface porosity of more than $5 \%$, leveling with putty in the range of $50 \%$ of the area and above is required [4,5]. The different surface porosity of the cement substrate leads to a change in the water-retaining capacity of paint, and consequently, to a different quality of the appearance of the coatings.

Research has shown that the quality of the appearance of coatings is determined by the nature of the bottling of the paint. In accordance with [6] bottling is considered as a rheological process, which can be described by the following expression:

$$
h=\frac{b^{2} f}{8 \sigma}
$$

where $h$ - stroke height;

$b$-width of stroke;

$f$ - shift limit stress of the paint;

$\sigma$ - surface tension of the paint.

\footnotetext{
* Corresponding author: loganin@mail.ru
} 
To create a model that takes into account the influence of factors that determine the quality of the appearance of coatings, various methods of experiment planning are used. In this case, as a rule, the form of the mathematical model is a complete form of the previously chosen regression equation, or its fragment, for example, a model of the form

$$
y=a_{1} x_{1}+a_{2} x_{2}
$$

or

$$
y=a_{11} x_{1}^{2}+a_{22} x_{2}^{2}+a_{12} x_{1} x_{2} .
$$

The exclusion of certain members from the model is associated with rigorous procedures for determining the significance of the coefficients.

Such an approach is universal for any output factor y and does not require any additional knowledge about the studied factor as an obligatory element.

Among the shortcomings of this approach are the following points:

- there is a possibility of output of the calculated value for physical and logical limits during interpolation of model ;

the absurd results can be observed when substituting zero values separately for factors $\mathrm{x}_{1}$ and $\mathrm{x}_{2}$, even if these conditions were within a given interval of their experimental study.

It is of interest to consider, when developing a quality of model of appearance of coatings, the application of experimental planning methods based on combining probabilistic and deterministic approaches. In our opinion, the most optimal for describing the model is the multi-factorial function of Protodyakonov of the following kind [7]

$$
Y=\frac{1}{y_{\text {aver }}} y_{1}\left(x_{1}\right) y_{2}\left(x_{2}\right)
$$

$$
\text { where } \begin{aligned}
y_{1}\left(x_{1}\right), y_{2}\left(x_{2}\right) \quad & \text { - particular algebraic dependencies on the } \\
& \text { factors } x_{1} \text { and } x_{2} ; \\
& \text { particular algebraic dependencies on the factors and } \\
y_{\text {aver }} & \text { - the average value of all the experimental results taken } \\
& \text { into account. }
\end{aligned}
$$

As a structural basis, the following experiment plan is proposed (Table 1).Each line of the plan represents the specific conditions and result of the experiment. An important advantage in this case is that there are no restrictions on the kind of particular algebraic dependence.

Under conditions of uncertainty, it is possible to use additional a priori information related to the physical meaning of the studied dependence (increase, decrease, extremality, or certain boundary conditions).

If there is no physical concept regarding the influence of this factor or its nature is unclear, then it is necessary to limit the processing of the obtained data by the least squares method to the equation of the straight line. If necessary, the adequacy of particular dependencies is checked. 
Table 1. A two-factor experiment at three levels

\begin{tabular}{|l|l|l|}
\hline N experience & $\mathrm{X}_{1}$ & $\mathrm{X}_{2}$ \\
\hline 1 & 1 & 1 \\
2 & 1 & 2 \\
3 & 1 & 3 \\
4 & 2 & 1 \\
5 & 2 & 2 \\
6 & 2 & 3 \\
7 & 3 & 1 \\
8 & 3 & 2 \\
9 & 3 & 3 \\
\hline
\end{tabular}

Another important advantage of the model (4) is that the value of the multifactor dependence corresponds exactly to the zero value of the partial dependence. The influence of particular functions on the multifactor dependence can be perceived as a shift of it from the mean value in proportion to the relative change in the particular functions.

In the work are given are the results of the experiment and the calculation of the quality model of the appearance in the example of a polymer lime coating, depending on the surface tension of the paint and the quality of the cement substrate

\section{Materials and methods of research}

In the work used lime, polymer calcareous, polyvinyl acetate cement PVAC paint. Quality of the cement substrate was estimated by the surface porosity index

$$
P=\frac{S_{\text {por }}}{S_{\text {subst }}} \cdot 100 \%
$$

where $S_{\text {por }}$ - area of pores on the surface of the substrate, $\mathrm{cm}^{2}$;

$S_{\text {subst }}{ }^{-} \quad$ total surface area of the substrate, $\mathrm{cm}^{2}$

Variable factors were: $\mathrm{x}_{1}$ - surface porosity of the substrate, $\%$, and $\mathrm{x}_{2}$-surface tension, $\mathrm{mJ} / \mathrm{m}^{2}$, output parameter Y-surface roughness, which was assessed using the Model 283 profilometer

\section{Results of researches}

In Table. 2 shows the experimental data of an estimation of a roughness of coverings depending on investigated factors. Particular point dependencies are presented in Figs. 1, 2 .

The results of a study of the roughness of the surface coatings (Table 2) on a smooth glass skimmed surface with zero porosity and on a cement surfaces with different porosity, confirm the assumption that the quality of the substrate, and it is the degree of its homogeneity, the presence or absence of impurities on its surface, its porosity exert a significant influence on the quality of the appearance of the coatings formed, and thus on the protective properties of coatings. 
Table 2. Infusion of the porosity of the substrate on the quality of the coating

\begin{tabular}{|l|c|c|c|}
\hline Type of coating & $\begin{array}{c}\text { Porosity of the } \\
\text { substrate, } \%\end{array}$ & $\begin{array}{c}\text { Roughness of } \\
\text { coatings, } \mathrm{mkm}\end{array}$ & Quality class of appearance \\
\hline Lime & 0 & 33,9 & $\mathrm{~V}$ \\
& 5,7 & 50,5 & $\mathrm{~V}$ \\
\hline polymer- & 9,6 & 83,4 & $\mathrm{VI}$ \\
calcareous & 0 & 33,5 & $\mathrm{~V}$ \\
& 4,1 & 41,3 & $\mathrm{~V}$ \\
\hline PVAC & 11,9 & 88,1 & $\mathrm{VI}$ \\
& 0 & 4,5 & $\mathrm{~V}$ \\
& 3,09 & 14,5 & $\mathrm{~V}$ \\
\hline
\end{tabular}

It is obvious, that an increase in porosity from 3 to $5 \%$ to $10-12 \%$ leads to a deterioration in the quality of the appearance of the coatings.

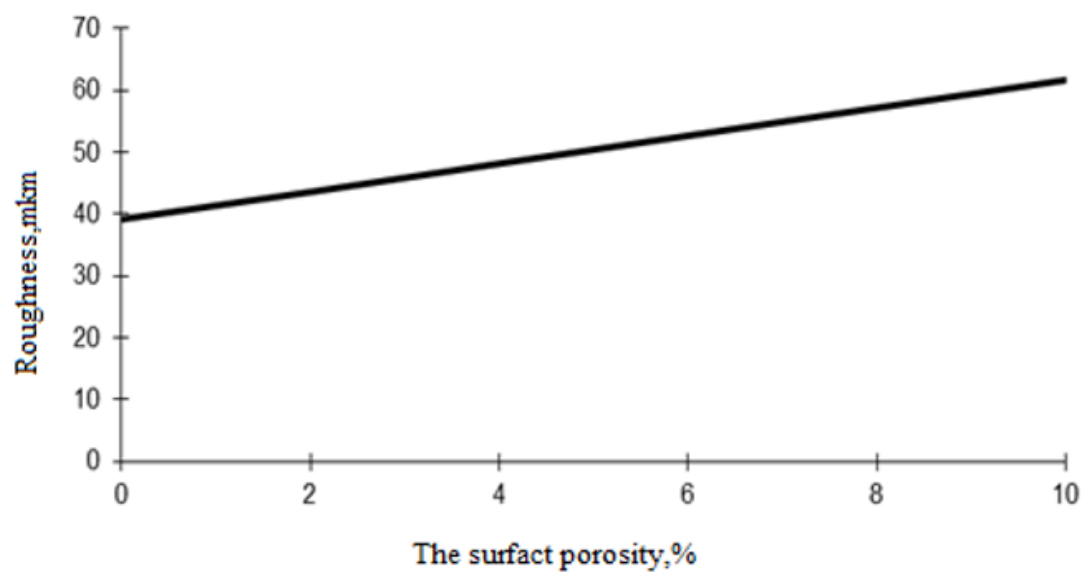

Fig. 1. Effect of the surface porosity of the cement substrate on the quality of the appearance of the polymer calcareous coating

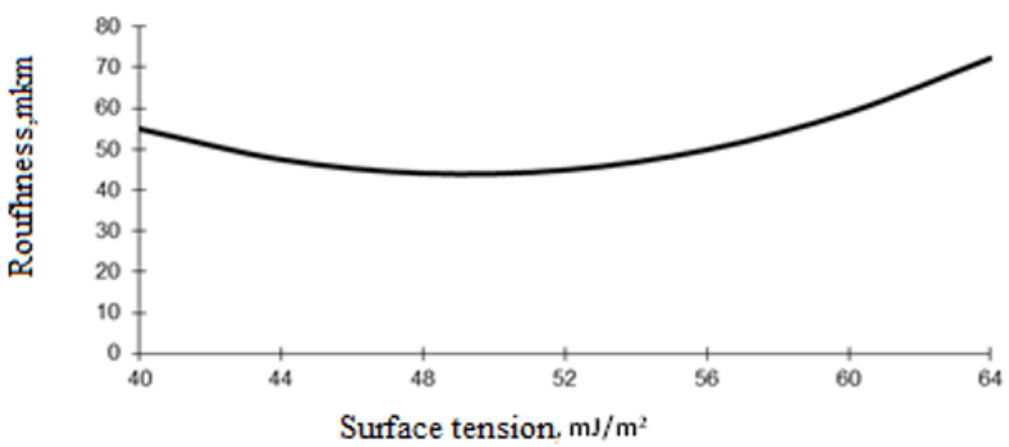

Fig. 2. Influence of surface tension of polymer calcareous paint on the quality of the appearance of the coatings 
The results of the studies ( Fig. 1, 2) can be approximated by the following functions

$$
\begin{gathered}
y_{2}=359-12,83 x_{2}+0,13 x_{2}^{2} \\
y_{1}=39,15+2,23 x_{1}
\end{gathered}
$$

The significance of particular dependencies was determined from the correlation coefficient. The Protodyakonov equation of significant private functions has the form

$$
Y=\frac{1}{51.039}\left(39,15+2,23 x_{1}\right)\left(359-12,83 x_{2}+0,13 x_{2}^{2}\right)
$$

and gives results that correlate well with experimental (for polymer calcareous coating) (Table 3). The correlation coefficient is 0.98 .

Table 3. The influence of various factors on the quality of appearance polymer calcareous coating

\begin{tabular}{|l|l|l|}
\hline$x_{1}$ & $x_{2}$ & $Y_{\text {calc. }} / Y_{\text {exp. }}$ \\
\hline 0 & 40 & $40 / 41,299$ \\
0 & 50.8 & $33,3 / 32,793$ \\
0 & 60.63 & $43,5 / 45,289$ \\
4.1 & 40 & $48 / 50,944$ \\
4.1 & 50.8 & $41,3 / 40,452$ \\
4.1 & 60.63 & $56,55 / 55,865$ \\
11.9 & 40 & $72 / 69,293$ \\
11.9 & 50.8 & $51,2 / 55,021$ \\
11.9 & 60.63 & $73,5 / 75,987$ \\
\hline
\end{tabular}

Note. $Y_{\text {calc. }}$ - roughness values of the coating surface, obtained by calculation in accordance with the model (4); $Y_{\text {exp. }}$ - surface roughness values of the coating obtained experimentally

Thus, the Protodyakonov formula adequately describes the joint effect of the surface tension of the paint composition and the surface porosity of the substrate on the quality of the appearance of the coatings, taking into account their physical meaning.

\section{Conclusions}

The regularities of the formation of the quality of paint coatings on a cement substrate are established. It is shown that with an increase in the surface tension of the aqueous paint composition, a lower quality of appearance is observed. With an increase in the porosity of the substrate, an increase in the surface roughness of the coatings is observed. A model of the appearance quality of coatings is proposed depending on the porosity of the substrate and the surface tension of the paint composition

\section{References}

1. L.A. Sukhareva. The durability of coatings. Moscow, Chemistry, 240 (1984)

2. V.I. Loganina. Model for Predicting Protective and Decorative Exterior Walls. Contemporary Engineering Sciences, 8( 2) 77-84 (2015) 
3. S.A.Nikulin, V.G. Khanzhin, A.B. Rozhnov. Analysis of crack resistance and quality of thin coatings by acoustic emission. 8th International Conference of the SlovenianSociety-for-Non-Destructive-Testing on the Application of Contemporary NonDestructive Testing in Engineering .Portoroz, SLOVENIA.8th International Conference of the Slovenian Society for Non-Destructive Testing, Conference Proceedings: Application of contemporary non-destructive testing in engineering 309-316 (2005)

4. V.I. Loganina. Economic Estimation of Quality Process of Coloring Building Products and Designs. Contemporary Engineering Sciences, 8 (2) 71-75 (2015)

5. V.I. Loganina, E.I. Kuimova, T.V. Uchaeva. Application of the Fuzzy Preference Relation in the Evaluation of the Competitiveness of Dry Lime Mortar. Applied Mathematical Sciences, 9( 4) 177-184 (2015)

6. A.I. Bykhovsky. Spreading. Science. Doomka. 102(1983)

7. M. M Protodyakonov, R. I. Teder. Method of rational planning of the experiment. Moscow, Science (1970) 